\title{
ТЕОРЕТИЧЕСКИЕ АСПЕКТЫ СИСТЕМЫ УПРАВЛЕНИЯ КАЧЕСТВОМ
}

\author{
(c) 2021 Ахмадьянова P.P. \\ студент \\ Финансовый университет при Правительстве Российской Федерации, Россия, Москва \\ E-mail: rufa_br@mail.ru \\ (c) 2021 Лялькова Е.Е. \\ Кандидат экономических наук, доцент, доцент Департамента бизнес-аналитики \\ Факультета налогов, аудита и бизнес-анализа, \\ Заместитель заведующего кафедрой «Современные технологии сбора и обработки отчётности» (МШБ) \\ Финансовый университет при Правительстве Российской Федерации, Россия, Москва \\ доцент кафедры «Бухгалтерского учёта и налогообложения» \\ РЭУ им. Плеханова, Россия, Москва
}

В настоящей статье рассмотрены основные аспекты системы управления качеством. Приведены основные документы системы менеджмента качества различных уровней и история становления управления качеством в России. Отдельное внимание уделено системе «Бережливое производство» и её компонентам.

Ключевые слова: система управления качеством, стандарты, контроль, менеджмент качества, управленческий учёт и отчётность

В современном мире требования к продукции и услугам становятся строже, а производители стремятся тщательно контролировать качество произведённой продукции, чтобы удовлетворить нужды покупателей.

Контроль качества каждого цикла производства становится всё больше необходимым, а, следовательно, соответствие работников предприятия предъявляемым требованиям и характеристикам становится обязательным.

Задача системы управления качеством улучшать качество продукции предприятия и соотнести его с ожиданиями потребителей, при этом формируется не контроль единицы произведённой продукции, а производственный процесс, в котором отсутствуют ошибки, просчёты и брак, приводящие к плохому качеству.

Формирование эффективной системы управления, составной частью которой является менеджмент (управление) качеством, необходимо для успешной деятельности экономического субъекта. В основу формирования вышеупомянутой системы могут быть положены международные стандарты ИСО серии 9000 [7].

Цели в области качества являются такими же важными для предприятия, как цели связанные с развитием, финансированием, рентабельностью, окружающей средой, охраной труда и безопасностью.

Управление качеством экономического субъекта предполагает системный подход, который включает в себя анализ требований конечного потребителя и определяет процессы, которые позволят добиться получения качественной продукции.

В целом множество подходов к управлению качеством можно подразделить на два основных направления.

Административный подход предполагает повышение качества выпускаемой продукции до 100\%. Брак при таком подходе рассматривается как крупное происшествие, требующее устранение любой ценой. Меры по предотвращению образования дефектов и доведению уровня качества до 100\% существуют для всех видов дефектов.

Экономический подход опирается только на экономическую точку зрения. Как и в административном подходе, меры по предотвращению образования дефектов проводятся, но уровень качества выпускаемой продукции зависит от величины затрат на ее достижение. Рубль, который был вложен в обеспечение качества на начальном этапе работы может принести десятки и даже сотни рублей дохода.

Система управления качеством состоит из следующих элементов, представленных на рисунке 1. 


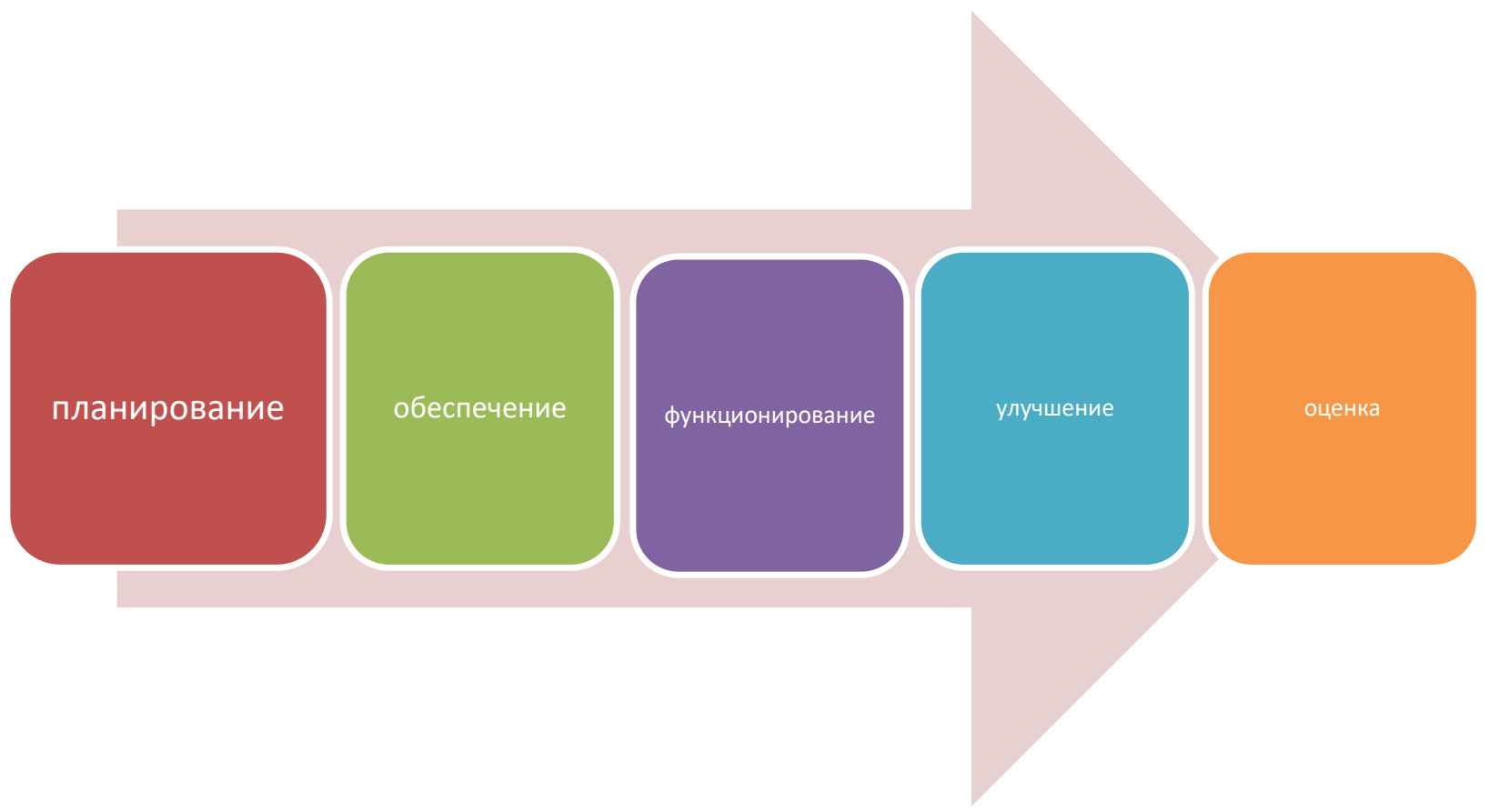

Рисунок 1. Элементы системы управления качеством

Основные документы системы управления качеством:

- политика в области качества и приложения к ней;

- документы по организации планирования;

- документы по осуществлению процессов и управления ими.

На данный момент вопрос обеспечения качества является достаточно актуальным. Это связано с тем, что продукция дорожает и усложняется, а стоимость её комплектующих частей постоянно растёт. Такая тенденция обращается к истории развития системы качества. История возникновения систем управления качеством ведет к началу индустриальной революции, когда был развит однотипный вид деятельности. По мере развития науки, техники и технологий - предприятия увеличивались, владельцы перестали присутствовать лично на производстве, и передали полномочия назначенным лицам. Важность вопросов качества возрастала, ведь ошибка в производстве могла стать причиной катастроф и гибели населения. Это привело к необходимости внести изменения в подход к управлению, а именно создание отделов контроля качества. Эти отделы стали осваивать различные области: стандартизация, предупреждение ошибок и анализ жалоб потребителей.
В 1987 году Международная Организация Стандартизации (ISO (ИСO) InternationalStanda rdsOrganization) издала серию моделей систем менеджмента качества, чтобы дать возможность мировому сообществу стандартизировать общий пакет требований систем менеджмента качества и, таким образом, облегчить выравнивание торговых барьеров, основанных на недостатке приемлемости или понимания различных национальных документов Системы менеджмента Качества (СМК). Они стали известны как серия ISO 9000.

При рассмотрении истории становления управления качеством в России можно выделить три этапа развития:

1. Российская Империя (XVIII-XIX века). В данный период началось зарождение системы управления качеством, а именно приняты первые нормативные акты в данной области.

2. Советский Союз (1917-1991 гг.). В это время система менеджмента качества приобретает статус отдельной науки на государственном уровне

3. Российская Федерация (с 1991 года и по настоящее время). Качество становится фундаментальной социально-экономической категорией, которая выходит на передний план [8].

Внутренняя управленческая отчётность выступает основным инструментом системы 
управления качеством и представляет по своей сущности набор отчётов компании. Главная её задача: предоставить руководству и собственнику актуальные сведения о текущем положении дел в компании. Внутренняя управленческая отчётность показывает итоги деятельности работы компании как в целом, так и в разрезе подразделений, дочерних организаций и дополнительных направлений деятельности. Формирование такой отчётности является добровольным и государством не регламентируется.

В 1980 году в космической индустрии США для контроля (обеспечения) качества и безопасности продуктов питания для космонавтов была разработана Система НАССР (анализ рисков и критические контрольные точки). Данная система широко распространилась в пищевой промышленности США и стран Евросоюза. В России добровольная система сертификации НАССР зарегистрирована в 2001 г. (ГОСТ Р 51705.1-2001). Система НАССР - это совокупность организационной структуры, документов, производственных процессов и ресурсов, необходимых для реализации системы управления качеством.

В нашей стране к версии системы НАССР предъявляются следующие требования:

- учёт действующих государственных нормативных документов при выборе потенциально опасных факторов;

- выявление источников информации;

- учёт действующих схем производственного и санитарного контроля;

- комплексный подход к управлению безопасностью продукции;

- обучение группы аудиторов;

- алгоритмизация экспертных решений.

Система менеджмента безопасности пищевой продукции включает в себя следующие общепризнанные ключевые элементы:

- интерактивный обмен информацией;

- системный менеджмент;

- программы предварительных и обязательных мероприятий;

- принципы HACCP (Hazard Analysis and Critical Control Points - Анализ рисков и критические контрольные точки).

Для повышения результативности системы менеджмента безопасности пищевой продукции необходимо проанализировать опасности. Проведение такого анализа позволит получить знания, которые нужны для разработки эффективной комбинации мероприятий по управлению.
Система «Бережливое производство» - это модель оптимизации производства (lean production), которую разработали в Японии, она активно внедряется на российских предприятиях. В России уже в 2000 году начали внедрять методы бережливого производства, происходило это путём вовлечения передовых предприятий и небольших компаний, которые искали пути снижения издержек в условиях высокой инфляции. К примеру, АО «КамАЗ» - крупнейший производитель тяжёлых грузовых автомобилей в России начал внедрение бережливых практик в 2005 году. Этот метод помог выявить и удалить устаревшие станки, оптимизировать использование земельных участков. В результате в 2009 году увеличился объем выпуска продукции почти в два раза (23 автомобиля в час вместо 10) [1].

Пивоваренная компания «Балтика» внедрила метод бережливого производства на своих предприятиях с 2011 года. В результате была произведена переналадка (SMED) в цехе розлива и на данный момент замена одного из самых часто используемых видов оснастки теперь проходит за 28 минут, а ранее на замену требовалось 45 минут. Поломки оборудования сократились на 45\%, увеличился коэффициент эффективности применения на 3,2\%. Регламентация производственных действий рабочих, введение четких протоколов и рекомендаций помогла снизить число операций на $48 \%$.

В РЖД программа реализуется с 2010 года, оптимизация технического обслуживания подвижного состава и исключение дублирования операций по обслуживанию грузовых вагонов помогло сэкономить 2,7 млн. рублей. В РЖД за 2019 год практиками lean было охвачено 1533 подразделения, а внедрение показало экономический эффект размером 1,7 млрд. рублей.

Практику бережливого производства применяют в финансовой сфере. В 2011 году Сбербанк запустил проект «Биржа идей», в котором любой сотрудник мог предложить улучшение в рабочем процессе, а после успешной реализации идеи получал премию. В результате за пять лет реализации такой идеи банк сэкономил 350 млн. рублей. «Сбербанк» создал lean-лаборатории, которые ведут непрерывный мониторинг производственных процессов.

Ожидается распространение практик бережливого производства на новые отрасли экономики. В условиях высоких издержек и слабого спроса принципы бережливости придут в сферу 
услуг, офисную часть предприятий, бухгалтерию, ИТ-отделы. Будет актуальна государственная поддержка внедрения lean-практик в виде информационной помощи, создания коммуникативной сети обмена опытом, ликбезы теоретиков и практиков данной модели через государственные каналы связи и площадки.

Первый принцип «точно вовремя» применяется в работе на конкретного потребителя. Компания не создаёт больших товарных запасов, а работает под заказ: при получении заказа на автомобиль на его производство изыскиваются ресурсы, привлекается рабочая сила, налаживаются связи с поставщиками. В итоге создаётся оптимальный продукт, себестоимость которого не обременена масштабом производства в части нерациональных затрат.

Второй принцип автономизации реализуется при сокращении временных потерь путём оптимизации переналадки и переоснащения оборудования. Здесь была создана практика моментальной переналадки (Single Minute Exchange of Die, SMED), которая была направлена на быструю перенастройку или пере- зарядку оборудования.

Третий принцип «дзидока» формирует производственные процессы абсолютно понятные рабочим. Для этого пространство предприятия нуждается в правильной разметке, навигации, указателях, границах рабочих зон, путях транспортировки. Руководство компании должно отправляться на «реальные места», а именно начальники цехов, главные инженеры и мастера участков должны непрерывно наблюдать за происходящим на производстве и выявлять слабые звенья в цепи.

Современная методология систем управления качеством взаимосвязана с проблемами качества продукции и с управленческой деятельностью, ответственной за поддержание требуемого уровня качества. Поэтому системы управления качеством получили обширную область применения, которая распространяется на все этапы жизненного цикла производства. Управление качеством обеспечивает производственную деятельность экономического субъекта минимальными затратами и максимальной прибылью.

\section{Библиографический список}

1. Блинкова Е.С., Мечик С.В., Рябков А.В. Бережливое производство как инструмент повышения эффективности предприятия нефтегазовой отрасли // Научный диалог: экономика и управление. 2018. URL: https:/ interactive-plus.ru/ru/article/130316/discussion_platform.

2. Васин С.Г. Управление качеством. Всеобщий подход: учебник для бакалавриата и магистратуры / С. Г. Васин. - Москва: Издательство Юрайт, 2019. - 404 с. - (Бакалавр и магистр. Академический курс).

3. Горбашко E. А. Управление качеством: учебник для вузов / Е. А. Горбашко. - 4-е изд., перераб. и доп. - Москва: Издательство Юрайт, 2021. - 397 с. - (Высшее образование).

4. Горленко О.А. Статистические методы в управлении качеством: учебник и практикум для вузов / О.А. Горленко, Н. М. Борбаць; под редакцией О.А. Горленко. - 2-е изд., испр. и доп. - Москва: Издательство Юрайт, 2021. - 306 с. - (Высшее образование).

5. ГОСТ Р 51898-2002. Аспекты безопасности. Правила включения в стандарты - Справочно-правовая система «Консультант Плюс»: Законодательство: Версия Проф. - Текст: электронный. - URL: http://www. consultant.ru/document.

6. ГОСТ Р ИСО 9000-2001. Системы менеджмента качества. Основные положения и словарь. - Справочноправовая система «Консультант Плюс»: Законодательство: Версия Проф. - Текст: электронный. - URL: http://www.consultant.ru/document.

7. Ерохина А. В. Истоки эволюции системы управления качеством // Статистика и экономика. 2011. № 2. URL: https://cyberleninka.ru/article/n/istoki-evolyutsii-sistemy-upravleniya-kachestvom.

8. ИСО 9001:2000. Системы менеджмента качества. - Справочно-правовая система «Консультант Плюс»: Законодательство: Версия Проф. - Текст: электронный. - URL: http://www.consultant.ru/document. 